\title{
A estatuária como cultura material constitutiva de espacialidades nas áreas rurais missioneiras
}

La estatuaria como cultura material constitutiva de espacialidad en las zonas rurales misioneras

The statuary as material culture constitutive of spatialities in rural áreas

Jacqueline Ahlert*

Luiz Carlos Tau Golin**

\section{Resumo}

Este artigo trata da estatuária como cultura material constitutiva de espaços nas áreas rurais das doutrinas fundadas por jesuíticas e indígenas na América meridional. Considera-se a complexidade da criação desses contornos em sua significância relacional e sua remanescência. As regiões que abrangiam as antigas estâncias e chácaras missioneiras conservam imagens em madeira que pertenceram a capelas e ermidas espalhadas pelos postos e assentamentos campesinos. A permanência desse fragmento da cultura material, que compunha e caracterizava os espaços missionais, somada às referências encontradas na documentação primária e às contribuições teórico-metodológicas fundamentadas na ótica da espacialidade, problematizada por Tilley (1994) e Santos (2014), conduzirão as aproximações com os senti- dos e condicionantes da construção dos espaços extra doutrinas, agenciado por indígenas.

Palavras-chave: Cultura Material. Estâncias. Estatuária. Missões Jesuíticas.

\footnotetext{
Doutora em História pela Pontifícia Universidade Católica do Rio Grande do Sul, Brasil. Professora do Programa de Pós-Graduação em História da Universidade de Passo-Fundo, Brasil. E-mail: ahlert@upf.br

* Doutor pela Pontifícia Universidade Católica do Rio Grande do Sul, Brasil. Com pós-doutoramento em História na Universidade de Lisboa, Portugal. Professor do Programa de Pós-graduação em História da Universidade de Passo-Fundo, Brasil. E-mail: golin@upf.br
}

Recebido em 03/09/2016 - Aprovado em 10/11/2016 http://dx.doi.org/10.5335/hdtv.17n.1.7239 


\section{A conformação de uma espacialidade missioneira}

Quais seriam as alternativas metodológicas para mesurar e descrever espaços fluidos, fronteiras difusas, pontos abstratos distribuídos em mapas coloniais?

Noções de localização podem ser acessadas nos escritos jesuíticos, na iconografia elaborada por padres e indígenas, e mesmo na aplicabilidade a coordenadas de latitude e longitude apontadas por GPS. Entretanto, circunscrever pontos de referência não satisfaz o desvelar dos dilemas espaciais vinculados ao agenciamento humano da apropriação do meio.

Os lugares, como marcos iniciais, são muito mais do que pontos ou locais. As experiências geográficas começam no lugar, estendem-se por meio dos espaços e criam paisagens ou regiões. Conforme Tilley (1994), a identidade pessoal e cultural está ligada ao lugar, tendo ele significados e valores distintos para as pessoas. Sob esta ótica, o estudo topográfico (topoanalysis) abarcaria a compreensão da criação de auto-identidades perpassadas pelo lugar ${ }^{1}$, enquanto o espaço é um produto contextualmente constituído por relações entre as pessoas e dessas com os lugares. Está centrado nas práxis diárias dos indivíduos, articulando o cognitivo, o físico e o emocional (TILLEY, 1994). É, assim, um resultado da inseparabilidade entre sistemas de objetos e sistemas de ações (SANTOS, 2014). ${ }^{2}$

A complexidade da compreensão dos espaços por esse viés decorre da dimensão subjetiva que possuem, incompreensível fora das vivências simbolicamente construí- das pelos atores sociais. Para decodificar as representações oriundas do ajuste entre as demandas impostas pelo sistema jesuítico-colonial e sua assimilação pelos indígenas missioneiros, partiremos da noção de totalidade como categoria analítica capaz de mediar uma aproximação epistemológica do espaço (SANTOS, 2014, p. 73), numa abordagem voltada ao lócus material e à conformação simbólica consequente, na dialética entre o imaginário e os dados empíricos e na estruturação da experiência humana e das respostas às imposições do contexto histórico.

No que tange ao lócus material, a existência das estâncias justificava-se por serem formas de ocupação territorial, em sua complexidade organizacional de sedes povoados, rancherios de invernadas, lavouras de manutenção alimentar e unidades de produção pecuária - com predominância sobre a criação de gados vacum, cavalar, muar e ovino. Seus extensos rebanhos estavam destinados ao abastecimento dos povoados interioranos, às cidades missioneiras e à exportação, especialmente por meio do beneficiamento do couro e do uso dos chifres para confecção de utensílios domésticos.

As demarcações territoriais das estâncias, bem como as das chácaras, estavam atreladas à fundação das cidades e dos povoados durante toda vigência administrativa jesuítica.

Ao introduzirem missões religiosas na América Meridional, os inacianos depararam-se com um imenso espaço onde seus limites de ocupação balizariam os territórios "civilizados" dos ocupados pelos "bárbaros", divisão espacial entre cristãos e "pagãos". A legitimação da posse, iniciava-se, 
geralmente, com a fixação de uma cruz de madeira. Símbolo do cristianismo, essa delimitava o território, primeiramente, como espanhol e cristão e, logo, como jesuítico. A esse espaço simbólico e geopolítico os indígenas fortaleciam a noção de pertença e, invariavelmente, invertiam o sentido, agregando os europeus ao seu direito natural de povos originários. Em alguns casos, tendo-se unicamente a existência da aldeia ou regiões de trânsito, "não se tratava de uma tomada de posse com vistas a estabelecer de imediato uma redução", posto ou estância, com a representação cristã, mas demarcar o território a ser ocupado na perspectiva da ampliação dos domínios da Companhia de Jesus (BARCELOS, 2006, p. 411). O marco serviria de referência aos índios missioneiros e, sobretudo, como aviso aos não reduzidos. Em 1670, em visita as vacarias do Uruguai, o padre Jacinto Marques seguia o protocolo, colocando "uma cruz naquele território, a qual ainda se conservava no ano de 1680, e foi vista por muitos índios, que ali foram vaquear" (MANUSCRITOS DA COLEÇÃO DE ANGELIS (MCA) [1669-1749], 1954, p. 413). ${ }^{3}$

O sistema de cultivo dos povoados era definido pela divisão a partir dos cacicados. ${ }^{4}$ Assim, "cada um dos vinte ou mais caciques" que formavam as parcelas das doutrinas recebia para a sua família extensa "uma porção de todo o território em que podiam plantar e colher conforme sua necessidade". A produção familial ainda podia-se subdividir para o esforço de casais (acrescidos de avós e filhos). O módulo territorial destinado ao conjunto de usos em benefício dos indígenas, conforme suas capacidades familiares e individuais de trabalho, era es- pecificado como abambaé (abá - índio; mbaé propriedade) (HERNANDEZ, 1913, p. 208). ${ }^{5}$

Aos "necessitados em geral, [...] enfermos, viúvas, órfãos", era destinada a produção do Tupambaé, ou seja, do campo comum. A esse domínio pertenciam os rebanhos de gado e o produto da manufatura da erva. Seus produtos podiam ser utilizados para socorrer povos vizinhos ou famílias cujas reservas do Abambaé houvessem acabado e ser, ainda, vendidos para ornamentação da igreja e pagamento de tributos (HERNANDEZ, 1913, p. 208).

No entanto, mais do que elemento de posse e usufruto dos loyolistas, as estâncias e chácaras constituíam-se em espaços indígenas, fosse pelo longo domínio físico-geográfico dessas paragens, fosse pelos sentidos e usos que tinham e seriam ressignificados nelas.

Os conflitos e a legitimação dos espaços andavam lado a lado desde a instalação dos primeiros núcleos destinados ao plantio e à pecuária. ${ }^{6} \mathrm{Na}$ segunda metade do Seiscentos, o cacique Don Thomas Potira, relatou ao ouvidor da Real Audiência de La Plata, Don Juan Blasquez de Valverde, que, para o povo de San Francisco Javier, havia a "necessidad se le senalassen tierras sufficientes para tener en ellas estancias de ganados, chacaras, y sembrados porque de tenerlas en cumunion con los índios de los demas pueblos sircunvecinos era ocasion de disgustos y discórdias entre ellos". Ao que os índios de Concepcion reagem advertindo que sua posse sobre a terra "entre el Uruguay e Yyiu" era um "derecho natural" (MCA, [1611- 1758], 1970, p. 31).

Em contrapartida, alegavam os índios de San Javier, lhes pertencer dito território, 
"pois fôra aí a estância de Nheçu, onde foram vitimados os Padres Roque, Afonso Rodriguez e João del Castillo", cujos povoadores, "mais tarde, temerosos da invasão bandeirante", se haviam trasladado para o povoado homônimo, com seu cacique, D. Francisco Nongi (PORTO, 1983, p. 322).

Os indígenas conheciam os lugares. $\mathrm{O}$ domínio milenar do território era algo que os inacianos valorizavam e do qual valiam-se para localização e planejamento estratégico. $\mathrm{Na}$ "Description de los Parajes cercanos al fuerte [Forte Jesus, Maria, José do Rio Pardo, localizado à margem esquerda do rio Jacuí, na confluência do rio Pardo, na elevação esquerda de sua foz] y de los rios de aquelas cercanias, y de sus duenos naturales" (1754), o padre Bernardo Nusdorffer oferece informações relevantes sobre a relação dos indígenas com a região: sua habilidade de representação iconográfica da topografia; o domínio histórico daqueles sítios - perpassado pelos anos e gerações -, e a mobilidade desses no amplo território além-doutrinas.

Para q el que leiere este escrito tenga alguna noticia de la tierra y sítios de q se habla me ha parecido conveniente dar en este lugar alguna description della, especialmente de los rios; no vendo yo esta description por la mas exacta, aunq algunos rios y parajes yo mismo los he visto con mis ojos, otros tengo de otros PP." q han estado en ellos, y otros se leen en ei P. Del techo y lo pintan en sus estancias los indios como estan, los quales ay se criaron y los han andado continuamente y los andan, assi quando van à los Yerbales y à sus estancias (MCA [1750-1802], 1969, p. 254) (grifo nosso). ${ }^{7}$
Figura 1 - Mapa Compuesto por un indio guarani y en el que se consignan las estancias de algunas reducciones

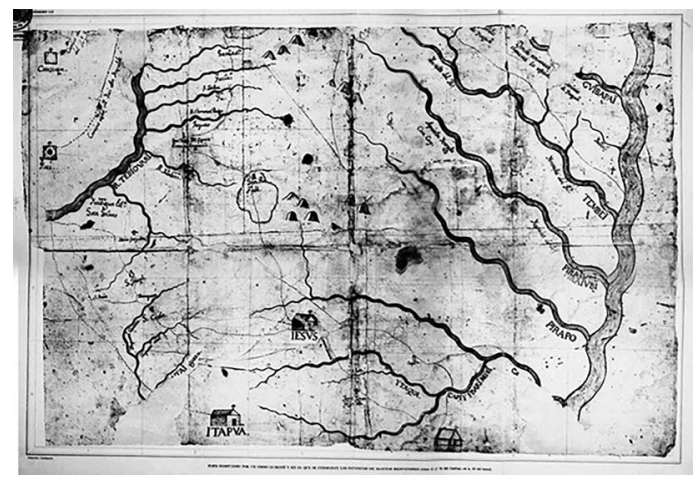

Fonte: FURLONG, 1936, Lâmina VII, n. 16 do Catálogo, p. 42 do texto. In: BARCELOS 2006. CD.

Carmen Curbelo (2014) assinala o desconhecimento do território por parte dos sacerdotes, observável na dificuldade de realizarem-se os inventários quando se concretizou a expulsão dos jesuítas. A arqueóloga atribui a situação ao distanciamento daqueles que conheciam e atuavam nesses espaços.

A presença dos curas era rara nas áreas rurais. Fosse nos domínios da Província Paraguaia, ou entre os chiquitos, os padres relatavam: "Es mucha canga y trabajo para el Cura", cuidar das doutrinas, chácaras e das estâncias (MCA, [1703-1751), 1955, p.122). Destarte, como ocorreu nos demais domínios missioneiros, o agenciamento indígena conduziu o processo formativo das "reduções", porquanto dois curas não poderiam impor um padrão de organização absoluto a milhares de indígenas. ${ }^{8}$

A qualidade da administração indígena variou durante a longa experiência inaciana na América do Sul, no entanto, a sua importância era destacada nas ânuas. "La experiência ha mostrado q nuestros Yndios 
lo ban haciendo mui bien", expõe o Padre José Paulo de Castanheda, em 1704 (MCA, [1703-1751), 1955, p.100).

As estâncias possuíam populações fixas em suas sedes e nos postos administrativos das invernadas, em cujos ranchos os altares domésticos ou a presença de estátuas certificavam o sistema missioneiro. Todavia, em períodos sazonais de rodeios e tropeadas, circulavam temporariamente tropeiros, alferes encarregados do controle contábil e das milícias. Um sistema de milícias permanente e volante, conforme os desafios, criou um tipo singular de homem campeiro e guerreiro, preparado para o pastoreio e a guerra. Indivíduos que protegiam seus corpos com santitos de madeira, os quais campeiravam e percorriam o território no enfrentamento de "infiéis", gaudérios, portugueses, castelhanos, e demarcavam posses em relação à disputa com outras reduções. Dependendo da estância, os residentes fixos podiam oscilar de dezenas a mais de uma centena de famílias, além dos campeiros e tropeiros. No conjunto era uma população formada por gerações, que acumulavam conhecimentos de pecuária, lavouras de subsistência, equitação para o trabalho e para a guerra de cavalaria e artilharia rústica, além de dominarem a espacialidade territorial. Nelas existiam uma complexa divisão do trabalho, de índios estancieiros (geralmente, caciques ou irmãos administradores), capatazes, posteiros, domadores, campeiros etc. Em tais espaços também se associava a divisão de funções de gênero e idade, a exemplo da manutenção de uma diversificada lavoura, pomares, e pequenos animais domésticos para a alimentação.
Cargos estratégicos tinham o cuidado criterioso dos missionários, muitas vezes atribuídos a alguma das irmandades da redução, a exemplo dos conflitos de jurisdição territorial, rebanhos que transitavam para estâncias de outros povos, e os conflitos com os índios "infiéis" e os gaudérios. Os alferes encarregavam-se da defesa e também do policiamento interno, tendo, invariavelmente, a capacidade de associar aptidão militar e diplomática. As estâncias missioneiras de fronteira mantinham milícias organizadas, operavam em conjunto entre elas, conforme a região, e contavam com reforços de tropas das cidades do Povo. Em 1707, por exemplo, a invasão da estância de Yapeyú pelos "infiéis" redundou no adestramento militar dos milicianos, a exemplo do que ocorrera em toda a fronteira missioneira. No ataque foram "mortas treze pessoas e levaram vinte e seis mulheres e mais algumas crianças como cativas, furtando no caminho quatrocentas éguas mansas e outro número de cavalos" (MCA [1611-1758], 1970, p. 238-9). Além da autonomia militar dos Povos, suas forças realizavam expedições fronteiriças associadas com tropas espanholas.

Tomando como exemplo o caso de Yapeyú, nota-se que as soluções pensadas pelo cura para resolver os conflitos e recuperar os cativos foram bastante elucidativas quanto ao relacionamento entre indígenas fiéis e infiéis, bem como entre reduzidos e não reduzidos. Primeiro, chamou os guenoas cristãos da redução de Jesus Maria, solicitando-os para que interviessem junto aos seus parentes infiéis, que se recusaram prontamente, "alegando com demasiada energia" e que aquilo era um falso testemunho, sendo que 
haviam sido outros, "os mbohas e yaros", os responsáveis. Convidou o cura, então, os caciques das imediações para uma conferência sobre o caso, "os quais não recusaram vir; porém, por melhor que fossem as argumentações, nada bastou para que escutassem". Seguiu-se a solução drástica da "guerra defensiva" contra os guenoas infiéis (MCA [1611-1758], 1970, p. 238-9).

A "população" missioneira fora das cidades sempre foi expressiva. Apenas como exemplo, no pós-período jesuítico, as estâncias continuavam funcionando articuladamente, administradas pelos indígenas. Registro de Gonzalo Doblas, de 1785, constata que nessas unidades de produção havia "pelo menos trinta índios, com suas mulheres, filhos e filhas". Regularmente, passavam de "setenta pessoas, ainda que não tenham que cuidar de mais de vinte mil animais" (1836, p. 23). No entanto, como em toda a sua história, era na época sazonal dos rodeios e de formação de tropas, que as estâncias inflavam realmente sua demografia.

Até a invasão luso-brasileira de 1801, que desencadeou o bárbaro fenômeno de destruição e apropriação missioneira, a convivência interétnica era constante nesses espaços, bem como entre indígenas reduzidos e seus parentes "del monte". Na estância supracitada, já no contexto das demarcações do Tratado de Madri, "estaban todos los infieles charruas, mohanes, yaros, guenoas y minuanes, refugiados, porq todos estaban mal con los espanoles, ni hallaban en otra parte sustento para vivir, sino con los índios Yapeyuanos sus parientes" (MCA, [17501802], 1969, p. 251).
Os espaços rurais propiciavam a manutenção do ethos indígena guerreiro e comunitário. A vivência com os parentes não reduzidos, a presença de nações distintas, as defesas estratégias do território e os embates com invasores estão descritas em inúmeras Cartas Ânuas.

Conformava-se um espaço que manteria seus sentidos de uso, ainda que com seus lugares reduzidos, após o início do processo de decadência missional no Paraguai. ${ }^{9}$ Seus marcos principais eram as sedes/povoados, os postos e, sobretudo, as capelas. Os remanescentes de suas fundações, em sua maioria, perderam-se na exposição ao tempo e/ ou as atividades humanas. Restam, substancialmente, as imagens que os compunham, como testemunhos iconográficos de práticas e traduções. ${ }^{10}$

\section{Capelas e imagens como elementos relacionais}
O espaço só pode existir como um con- junto de relações entre coisas ou lugares. Neste sentido, não há espaço que não seja relacional. O espaço é criado por relações sociais, objetos naturais e sociais (TILLEY, 1994, p.11).

As sedes das estâncias missioneiras constituíam-se de um núcleo populacional, com ranchos, galpões e capelas, com características de "povoados". Representavam unidades autossuficientes, na relação com a doutrina e demais áreas missionais.

A existência de capelas acrescia ao espaço o lócus do sagrado. Além disso, a definição de uma referência, de uma orientação. 
Os elementos básicos, que compunham o sentido de sua materialidade eram as imagens dos santos, fossem eles padroeiros da doutrina a que pertencia a estância, fossem entidades consagradas a labuta campesina.

Adentramos, assim, o âmbito da cultura material no espaço estancieiro. Considerando-a um "segmento do meio físico que é socialmente apropriado pelo homem". Segundo propósitos e normas culturais, a apropriação se faz por intervenções que dão função e sentido ao meio físico. Essa "ação, portanto, não é aleatória, casual, individual, mas se alinha conforme padrões, entre os quais se incluem os objetivos e projetos" (MENEZES, 1983, p.112). ${ }^{11}$

São compreendidos como objetos, além do arranjo espacial manipulado, as cercas, currais, casas, postos e demais suportes de desempenho das funções rurais. Objetos compósitos do espaço eram, ainda, as capelas e seus ornamentos, cujo conjunto formava, como cultura material, o núcleo religioso da zona.

Santos elucida a dialética dos objetos e espaços,

Sem dúvida, o espaço é formado de objetos; mas não são os objetos que determinam os objetos. É o espaço que determina os objetos: o espaço visto como um conjunto de objetos organizados segundo uma lógica e utilizados (acionados) segundo uma lógica. Essa lógica da instalação das coisas e da realização das ações se confunde com a lógica da história, à qual o espaço assegura a continuidade (2006, p. 24, grifo do autor).

Por essas razões, não se pode dissociar os espaços dos objetos que materializam sua existência, sendo esses articulados juntamente com suas funções e ações que lhe dão uso, onde há por conseguinte a presença de um conteúdo simbólico e discursivo e de um significado operacional ${ }^{12}$ que lhe dão sentido.

A presença das estruturas religiosas era parte fundamental da elaboração dos espaços missionais. Os povoados estavam repletos de capelas, altares improvisados, oratórios móveis e imagens de culto comum, familiar e pessoal (AHLERT, 2012).

Fora dos povoados, a presença de imagens fazia-se, sobretudo, nas chácaras e estâncias. Todos os postos das estâncias possuíam capelas. Ao percorrer parte das antigas estâncias jesuíticas em território oriental, em fins do século XVIII, o historiador Alejo Peyret escreveu: "Em San Miguel [posto da estância de Yapeyú], outro estabelecimento, outro oratório dos jesuítas [...]. Em Santa Tecla, outro estabelecimento, outro oratório" (1881, p. 64 e 66). Do mesmo modo que em Santa Maria, posto nas imediações do Rio Negro/URY.

O padre Domingo Muriel, nos apontamentos que realizou entre 1747 e 1767, enfatiza que

Además de los edificios construidos en las treinta Doctrinas, unos de piedra, otros de barro, unos más y otros menos perfectos, según la posibilidad de cada uno, todas las Doctrinas tienen algunos pagos o pueblecillos menores. En ellos hay una capilla para que ejerciten sus actos religiosos y de piedad unas cuantas familias que viven en cada pago con un alcalde y mayordomo indio. Y así como todas las Doctrinas tienen estos pueblecillos campestres, así también cada indio particular se fabrica su cabana, sus chacras o abambaés, que a las veces están bastante apartadas del pueblo, y a ellas se van por algún tempo (1919, p. 558). 
A devoção aos santos nos ambientes de cultivo estava intrinsecamente ligada às crenças ancestrais pela concepção de que fatores externos aos mecanismos funcionais do plantio e da colheita tinham "poderes" de intercessão no domínio das pragas, do tempo e da produtividade.

Os poderes da natureza e dos fenômenos naturais são transformados pelos indígenas em seres sobrenaturais [...]. Numa taxionomia ocidental corresponderiam a entidades inferiores, ou seja, divindades que atuam positiva ou negativamente sobre o ser humano. Esses seres são comumente chamados, hoje em dia, de espíritos. Além dos espíritos de plantas e de animais de caça, há também os guardas das matas e dos montes, o que é bastante significativo, já que a vegetação é concebida como uma espécie de pele ou de pelo do corpo da terra. Em muitos casos, os termos "espírito" e "dono" são usados como sinônimos pelos índios. "Os espíritos são os cuidadores e guardas, herekua, ijára, dos animais e das plantas", tenta explicar um indígena. Em vários grupos kaiová e paĩ-tavyterã, esses espíritos são chamados de "guardas do ser" (Tekojára). Eles são os guardas ou as donas do modo de ser de uma determinada espécie animal ou vegetal, bem como de alguma faculdade do ser humano. Os "guardas do ser", em algumas circunstâncias, parecem marcar o limite entre seres sobrenaturais e naturais. A diferença essencial entre ambos os seres seria que os sobrenaturais são seres completos, conhecedores de seu próprio modo de ser, enquanto que os naturais muitas vezes carecem de entendimento. A terminação jára, "dono", indica que os seres denominados sob o epíteto Tekojára são os que conferem características animistas à religião guarani (CHAMORRO, 2008, p. 165).

Sobretudo nos povoados, quando iam aos campos, as crianças levavam em procis- são, ao som de cânticos, a estátua de Santo Isidro, padroeiro dos camponeses.

Ao som de tambores se juntam todos os que são capazes de trabalhar, e os que têm ofício vão às suas oficinas [...], e os demais, ao som do mesmo tambor, vão como em procissão ao campo, levando consigo algum santo em um tablado, que comumente é Santo Isidro Lavrador, com quem os pobres índios têm especial devoção em todos estes povos, e chegando ao local de trabalho, colocam o santo em um lugar decente, $[. .$.$] e trabalham [...] até a meia tarde.$ Semelhantemente, as meninas por outro lado, carregam a Virgem ou outra imagenzinha e em procissão saem, trabalham, comem com suas Herequarás uns e outros (ESCANDON, 1965, p. 97).

Entre a intimidade e a afinidade com os santos, estava o esmero: "Levam, com a comida para o meio dia, [...] instrumentos para o trabalho e uma pequena estátua de São Isidro Lavrador, em seu andor, com sua caixa para protegê-lo quando chove" (CARDIEL, in HERNANDEZ, 1913, p. 107).

Além da imagem que era carregada para área de trabalho, nas chácaras e estâncias não poderiam faltar capelas para Santo Isidro, por vezes, acompanhado de sua esposa, Santa Maria de la Cabeza. "Cada estância jesuítica tem sua capelinha", notou Félix Azara, décadas depois da expulsão dos jesuítas do território espanhol. Nelas, os "estancieiros e guardas do gado [posteiros, campeiros de ronda] rezavam o rosário e outras orações, e aos domingos cantavam o kyrie [eleison], ${ }^{13}$ credo, prefácio e tudo o que se canta numa missa" (AZARA, 1873. p. 189 e 193). A terra para os guaranis, ancestralmente, ordenava e equilibrava-se no cosmos pelo canto e pela festa e, nas doutrinas, em 
grande parte, através do ritual cujo centro era a imagem, levada em procissão, presidindo o trabalho nos campos.

A terra recebe sua plenitude de seu fundamento religioso, baseado em um ato litúrgico realizado por "Nosso Primeiro Pai". A conservação do mundo consistia, consequentemente, em manter viva e atual essa liturgia [...]. Deixar de rezar e descuidar o ritual seria como tirar da terra seu próprio suporte, provocando sua instabilidade e consequente destruição (MELIÁ, 1991, p. 57).

O espaço não é e não pode existir dissociado dos eventos e atividades nos quais está implicado (TILLEY, 1994). As práticas, nessa perspectiva, demandavam estratégias diferenciadas de culto nas áreas rurais. A relativa distância dos curas, o habitus da religiosidade ancestral, a proximidade com segmento "não-reduzido" do mundo colonial, como mencionado acima, e as ressignificações da práxis produtiva, encontraram, gradualmente, adequações na apropriação dos segmentos físicos.

Apesar das esparsas visitas dos padres, a importância do espaço sagrado comum materializado pelas capelas mantinha-se fundamental, potencializando sua necessidade. No diário do engenheiro militar José Custódio de Sá e Faria, durante a demarcação (1752-1759) do Tratado de Madri (1750), a referência às capelas é numerosíssima. ${ }^{14}$ Essas edificações acabaram por se converter em postos de referência para os demarcadores e local de acampamento. Assim ocorreu nas margens do Jacuí, "onde havia uma capela de Santa Ana abandonada", e do Vacacaí-Mirim. Entre os povoados de São João e São Miguel, havia um caminho delineado por capelas, entre elas a ermida ${ }^{15}$ sempre presente na área rural jesuítica, de Nossa Senhora de Loreto, que era "toda feita com as mesmas medidas da capela donde Nossa Senhora recebeu pelo anjo a embaixada para Mãe de Deus" (FARIA apud GOLIN, 1999, p. 493). ${ }^{16}$

Após a Guerra Guaranítica e expulsão dos jesuítas, durante o abandono gradual dos missioneiros aos povoados, as estâncias constituíram um dos refúgios possíveis aos que não voltaram a viver nos montes ou queriam manter alguma relação, ainda que simbólica, com a antiga organização. As capelas representaram a possibilidade de manutenção de práticas religiosas e foram o meio através do qual se firmou certa devoção rural crioula da qual muitas imagens são remanescentes.

O mapa produzido pelo cabildo de La Cruz, em 1784, indica a existência de 57 capelas nos arredores das reduções de San Tomé, São Borja, La Cruz e Yapeyu. Percebe-se que elas estavam regularmente distribuídas no território. Suas distâncias, comumente, variavam de duas a sete léguas, possibilitando que a cada dia de caminhada, pelo menos uma, servisse de parada para realizar as orações ou acampamentos. 
Figura 2 - Detalhe do mapa produzido pelo cabildo de La Cruz, em 1784. Localizado no Archivo General de la Nación, em Buenos Aires. Sala IX, 22-8-2

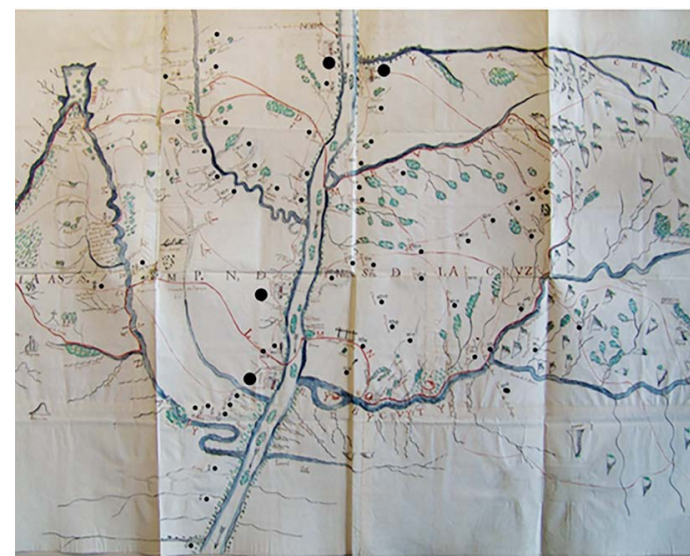

Fonte: BARCELOS, Arthur H. F. O compasso e a cruz. Cartografia jesuítica da América Colonial, 2006. CD

Legenda: os pontos pequenos indicam as capelas. As reduções de San Tomé, São Borja (acima, respectivamente a esquerda e a direita do rio Uruguai), La Cruz e Yapeyu estão sinalizadas por pontos maiores.

A referência às práticas religiosas nas capelas rurais é, comparativamente, rara. No entanto, há indícios do prosseguimento dos cultos nos povoados. Na doutrina de La Cruz, os sacramentos e liturgias católicas haviam sido apropriados e estavam sendo realizados pelos próprios índios. Aos domingos, "um jovem sacristão guarani celebrava o ofício vespertino; uma índia anciã conduzia o canto sendo acompanhada por dois violões, uma flauta e dois violinos". A atitude dos poucos índios e mestiços que chegavam a desolada igreja espantou o historiador Alejo Peyret, pois "indicava a devoção e as lembranças". O cemitério ao lado da igreja estava "muito bem cuidado e muitas tumbas antigas têm a lápide com seu epitáfio em guarani" (1881, p. 255).
Na mesma época (1882), viravam-se com o que dispunham os índios cristianizados instalados a léguas de La Cruz, em Santo Antônio da Palmeira, atual município de Palmeira das Missões. Eles estavam ali desde 1847, conforme o "Relatório do presidente da Província de S. Pedro do Rio Grande do Sul", redigido pelo senador conselheiro Manoel Antonio Galvão,

Ocorreu neste ano [1847], no distrito de Palmeira, onde tinha o tenente José Joaquim de Oliveira um campo: nos fundos dele apareceram em maio 200 índios de ambos os sexos: às expensas suas e com o que pode obter dos moradores da Cruz Alta, as solicitações do juiz municipal a quem escrevera, acudiu as primeiras necessidades dos novos hospedes. ${ }^{17}$

Nos períodos de crise, as estratégias missionais pareciam emergir na urgência de soluções que envolviam a sobrevivência. Nas estiagens eram usados "vários meios para pedir misericórdia e clemência divinas, suplicando por chuvas". Entre eles, eram organizadas "procissões e feitas orações especiais" (BESCHOREN, 1989, p. 79). O espaço continuava formado de objetos intercessores, entre o terreno e supraterreno, no âmbito móvel da cultura material e identitário do lugar onde se estabeleceram.

Das imagens processionais levadas para lá, algumas se encontram no Museu Vicente Pallotti, de Santa Maria, outras, em casas particulares de Cruz Alta.

A conclusão da igreja de Palmeira das Missões aconteceu somente em 1879. Durante esses anos, a maioria dos sacramentos era realizada autonomamente, mesclando o que havia de memória e o que sentiam fazer-se 
necessário nas liturgias do calendário cristão que sobrevinham.

\section{Consideracôes finais}

Como destacou Aurélio Porto, as estâncias e vacarias dos Povos Orientais ocupavam quase todo o atual território rio-grandense, "com exclusão apenas do trato de terra compreendido pela bacia oriental do Taquari, se bem que, no Planalto, estendam-se até os campos da Vacaria". Mesmo dentro desse trecho, "em plena Serra, estabelecem entrepostos de aproveitamento de grandes ervais nativos, que exploram intensivamente, como ocorre no Alto Uruguai, desde as manchas riquíssimas dõ Nhucorá, às cabeceiras do Rio da Várzea, até a Serra do Erval, no Sul" (PORTO, 1983, p. 320).

Permanecem em seus antigos postos as imagens. Algumas compondo acervos de museus municipais, outras em coleções particulares e várias em uso religioso, passados séculos do contexto no qual e para o qual foram criadas. Representam o espaço que constituíam como cultura material, as inúmeras evocações de Nossa Senhora, Jesus e dos santos, em Canguçu, Cerro Largo, Rio Pardo, Santiago, Ijuí, Alegrete, São Gabriel, Santa Maria, Passo Fundo, Santa Bárbara do Sul, etc.

$\mathrm{O}$ que legam as imagens são apenas fragmentos materiais de um passado - de sucessivos passados - cuja simples ilustração pouco responde. A articulação do espaço com a cultura material, como unidade mínima mediada e fabricada por um significado operacional e anímico (SANTOS, 2014), nos aproxima da dinâmica das relações, ultra- passando a história dos objetos para acessar aspectos da sociedade que os forjou.

\section{Abstract}

This article deals with statuary as a material culture constitutive of spaces in rural areas of doctrines founded by Jesuits and Indians in South America. It is considered the complexity of the creation of these contours in its relational significance and its remanence. The regions that included the olden cattle ranches and missionary farms retain wooden images that belonged to chapels and hermitages scattered throughout the posts and peasant settlements. The permanence of this fragment of material culture, which composed and identified the missionary spaces, together with the references found in the primary documentation and the theoretical-methodological contributions based on the optics of spatiality, discussed by Tilley (1994) and Santos (2014), will lead the approximations With the senses and determinants of the construction of the extra doctrinal spaces, acted by indigenous.

Keywords: Material Culture. Jesuit Missions. Cattle Ranches. Statuary.

\section{Resumen}

En este trabajo se analiza la estatuaria como cultura material constitutiva de espacios en las zonas rurales de las doctrinas fundadas por los jesuíticas y indígenas en sur de América Latina. Se considera la complejidad de la creación de estos contornos en su significado re- 
lacional y su remanencia. Las regiones que abarcaban las antiguas estancias de ganado y granjas misioneras conservan imágenes de madera que pertenecían a capillas y santuarios diseminadas en las estaciones y asentamientos campesinos. La permanencia de este fragmento de la cultura material, que formó e identifica los espacios misionales, además de las referencias encontradas en los documentos primarios y los aportes teórico-metodológicos basados en el punto de vista de la espacialidade, problematizada por Tilley (1994) y Santos (2014), conducirán las conjeturas sobre los sentidos y las condiciones de la construcción de los espacios extra-doctrinas, llevados a cabo por los indígenas.

\section{Palabras clave: Cultura Material. Estan-} cias. Estatuária. Misiones Jesuiticas.

\section{Notas}

1 Junto a Christopher Tilley, tais considerações estão ancoradas nos estudos de Edward Relph, cujo objetivo ao discutir a identidade dos lugares é entender a forma como a experiência dos lugares ocorre e seus componentes. Ele identifica pelo menos três componentes do envolvimento dos sujeitos com os lugares: a configuração física, as atividades e os significados (RELPH, 1976, p.47) RELPH, Edward. Place and placelessness. London: Pilon, 1976.

2 A relação entre espaço e lugar tem sido discutida e teorizada a partir de uma perspectiva particular dentro de uma 'escola' fenomenológica da pesquisa geográfica (Taun 1974, 1975, 1977; Pickel 1985; Relph 1976; Buttimer e Seamon 1980; Seamon e Mugerauer 1989). A principal preocupação nesta abordagem é a maneira pela qual lugares constituem espaços como centros do significado humano, sua singularidade de ser manifestada e expressada nas experiências do dia-a-dia e na consciência das pessoas dentro de vivências particulares.
3 Informação Jurídica, por meio de questionário e respostas de várias testemunhas, sobre o direito que têm os índios das Missões Guarani e Tape às Vacarias do Uruguai Ou Do Mar. H-Ix-1722.

Para melhor assistência a esses campos, que ocupavam largas extensões territoriais, estavam eles divididos em estâncias e estas em postos, em torno dos quais se erguiam pequenas capelas, e igrejas, algumas de relativa importância, que deram origem a cidades e importantes povoados rio-grandenses (PORTO, 1983, p. 330)

4 Como se sabe, "os parientes agrupados en diferentes cacicazgos, regían la division interna de la reducción y, en última instancia, también marcaban las disputas por el control de espacios. Puesto que la participación coordenada dependía de la lealtad basada en la inmediatez del parentesco, la emergencia de líderes reconocidos más allá de los límites de sus propios pueblos solo podía tener una existencia temporaria y efímera. Por lo tanto, las alianzas en torno de un gran líder respondían menos a una tradición de unificación que las particulares circunstancias de la guerra, que impedían a los cacicazgos afrontar la coordinación de las acciones por sí solos." (WILDE, 2009, p. 173).

5 O projeto de inserir o indígena num trabalho regular e que produzisse excedentes foi marcado por dificuldades e resistências, conforme relatos recorrentes nas correspondências ânuas e demais fontes. De acordo com Hernández, citando as reclamações de Cardiel, para evitar o abandono das chácaras e a produção insuficiente para o sustento do ano inteiro, "se mandava aos alcaides que percorressem as lavouras de cada um, para observar se eram suficientes e estavam em bom estado"; ainda assim, por vezes era necessário que o "cura saísse e vistoriasse" (1913, p. 208). Cf. SANTOS, Júlio R. Quevedo. A regulamentação do trabalho indígena nas Missões Jesuíticas. Revista Latino-Americana de História. Vol. 1, nº. 3, Março de 2012. Disponível em: <http://projeto.unisinos.br/rla/ index.php/rla/article/viewFile/66/44>.

6 A primeira estância para a criação de gados que se estabeleceu na Banda Oriental do Uruguai é a que pertenceu à Doutrina de São Xavier, nas terras fronteiras ao seu povo. A concessão tem a data de 10 de Julho de 1657 e é feita por Valverde (PORTO, 1983, p. 323).

7 De la relacion de lo succedido en estas doctrinas. Tercera parte de la relacion de lo succedido en estas Doetrinas, desde saliò delias el P.e Visitador Alonso Fernandez, hasta la retirada de los dos Exércitos Espanol y Português y fin del afio de 1754 . 
8 A partir de meados dos anos 1980, estudos sobre o agenciamento indígena nas Missões Jesuíticas problematizaram as tradicionais versões de um poder vertical imposto pela Companhia de Jesus.

9 O conhecimento do lugar deriva de experiências, sentimentos e pensamentos humanos. Espaço é uma construção muito mais abstrata do que lugar. Ele fornece um contexto situacional para os lugares, mas deriva seus significados de lugares particulares (RELPH, 1976, p.8). Sem lugares não podem haver espaços, e os primeiros têm significado ontológica primária como centros de atividade corporal, significado humano e apego emocional.

10 Sobre a qualidade perecível do material utilizado para construção de algumas habitações, o padre Domingo Muriel observou: En esos pueblecillos $\mathrm{y}$ en esas cabanas apenas alcanzan los ojos a ver más que cuero. Levántanse las paredes con estacas forradas de cuero. Todos los techos se cubren de cueros, y así duran tanto cuanto dura el tiempo seco, porque, en empezando a llover, se humedecen y arrugan los cueros y resulta la casa inhabitable (MURIEL, 1919, p. 558)

11 Pertencem a cultura material os artefatos, estruturas, o próprio corpo, na medida em que ele é passível desse tipo de manipulação ou, ainda, os seus arranjos espaciais.

12 Optou-se por utilizar o termo significado operacional para definir o modo particular como cada indivíduo cria um determinado objeto (HODDER, 2003).

13 Kyrie é um vocativo de origem grega da palavra "Senhor", traduzido livremente como "ó, Senhor", enquanto eleison é o imperativo aoristo do verbo "eleéo", que designa "ter piedade", "compadecer-se". No rito tridentino o Kyrie vinha recitado depois do ato penitencial.

14 O castigo infringido aos soldados que violassem as capelas era severo. Em março de 1756, quando os exércitos coligados luso-brasileiro e espanhol-platino passavam pelas imediações do arroio Vacacaí-Mirim, "alguns peões castelhanos e portugueses boliam nos trastes que haviam nas capelas dos índios". Imediatamente, foi determinado que "se daria em cada peão 100 açoites; e, sendo soldado, seis carreiras de vaquetas. Sua Excelência [Gomes Freire de Andrada] ordenou de sorte que servisse de exemplo aos mais: sendo peão, iria para galés; o que assim se distribuiu nas ordens". FARIA, José Custódio de Sá e. Diário da expedição e demarcação da América Meridional e das Campanhas das Missões do Rio Uruguai (1750-1761). In: GOLIN, Tau. A guerra guaranitica..., op. cit., p. 447.
15 A diferença entre ermida e capela não é substancial neste estudo. A ermida consiste numa edificação realizada numa área rural, para uso dos moradores do local. No caso das Missões Jesuíticas, as fontes denominam como capela estes espaços, sendo que, a termo, designaria espaços de culto público, na constituição inicial de um povoado.

16 Os trabalhos de campo para demarcação do Tratado de Madri ocorreram entre os anos 1752 a 1759. São inúmeras as capelas citadas, a exemplo das referências: “Neste Campo [de Santa Clara], achamos 3 ranchos de palha e um deles havia servido de capela". O mesmo ocorria no Campo das Vacas. "Achamos, neste Campo, 6 ranchos de palha. Um deles era capela. Esta tinha mais algum asseio do que as capelas que até aqui temos encontrado. Tem junto à porta uma cruz de pau, de altura de 6 palmos; e de fronte da mesma, outra mais alta, distante 20 braças. Tem junto um curral e a porta da capela fica para o sul" (p. 437 e 441). Além das capelas, os campos paraguaios já possuíam oratórios rurais particulares, de forma que "no povoado de Itá, na estância de Don José Garay, "há um oratório onde são rezadas missas". Ver: PARRAS, Pedro José de. Diario y derrotero de sus viajes, 1749-1753. España, Río de la Planta, Córdoba, Paraguay. Buenos Aires: Ed. Argentinas "Solar", 1943, p.191.

17 Relatório do presidente da Província de S. Pedro do Rio Grande do Sul, o senador conselheiro Manoel Antonio Galvão, na abertura da Assembléa Legislativa Provincial em 5 de outubro de 1847, acompanhado do orçamento da receita e despesa para o anno de 1847 a 1848. Porto Alegre, Typ. de Argos, 1847, p. 14. Disponível em: <http:// www-apps.crl.edu/brazil/provincial/rio_grande_do_sul>. Acesso em: 12 jan. 2017.

\section{Referências}

AHLERT, Jacqueline. Estátuas Andarilhas: as Miniaturas na imaginária missioneira: sentidos e remanescências. Tese de Doutorado em História. Porto Alegre: PUCRS, 2012.

AZARA, Félix de. Viajes inédito de Don Félix de Azara, desde Santa Fé a la Asunción, el interior del paraguay, y a los pueblos e Misiones. Revista del Rio de la Plata. Buenos Aires, 1873.

BARCELOS, Arthur H. F. O compasso e a cruz. Cartografia jesuítica da América colonial, 2006. 
. O Mergulho no Seculum: exploração, conquista e organização espacial jesuítica na América espanhola colonial. Tese de Doutorado em História. Porto Alegre: PUCRS, 2006.

BESCHOREN, Maximiliano. Impressões de viagem na Província do Rio Grande do Sul. Porto Alegre: Martins Livreiro, 1989.

CARDIEL, J. Breve relación de las misiones del Paraguay. In: HERNANDEZ, Pablo. Organización social de las doctrinas guaranies. v. 2. Barcelona: Gustavo Gilli, 1913.

CHAMORRO, Graciela. Terra madura, yvy araguyje: Fundamento da palavra guarani. Dourados/MS: Editora da UFGD, 2008.

CURBELO, Carmen, BRACCO, Roberto. La construccion del espacio missioneiro y la toponímia en territorio uruguayo, 2014. Disponível em: <http://www.ceibal.edu.uy/contenidos/ areas_conocimiento/cs_sociales/081024_estancias/estjesuiticas/rosariotoponimia.pdf>. Acesso: 20 jan. 2017.

DOBLAS, Gonzalo de. Memoria histórica, geográfica, política y económica sobre la provincia de Misiones de indios guaranis. Buenos Aires: Imprenta del estado, [1785] 1836.

FURLONG, S. J. G.: Juan de Escandón y Su Carta a Burriel, 1760. Buenos Aires: Theoria, 1965.

GOLIN, Tau. A guerra guaranítica: como os exércitos de Portugal e Espanha destruíram os Sete Povos dos jesuítas e índios guaranis no Rio Grande do Sul. Passo Fundo: EDIUPF; Porto Alegre: Ufrgs, 1999.

HERNANDEZ, Pablo. Organización social de las Doctrinas Guaranies de la Compañía de Jesús. Barcelona: Gustavo Gili Editor, 1913.

HODDER, Ian; HUTSON, Scott. Reading the past: Current approaches to interpretation in archaeology. Nova York: Cambridge, 2003.

MANUSCRITOS DA COLEÇÃO DE ANGELIS. Do Tratado de Madri à Conquista dos Sete Povos (1750-1802). Introdução, notas e sumário de Jaime Cortesão. Rio de Janeiro: Biblioteca Nacional, 1969.

MANUSCRITOS DA COLEÇÃO DE ANGELIS. Jesuitas e bandeirantes no Uruguai (16111758). Introdução, notas e sumário de Helio Vianna. Biblioteca Nacional: Divisão de Publicações e Divulgação, 1970.

MANUSCRITOS DA COLEÇÃO DE ANGELIS. Tratado De Madri Antecedentes-Colônia Do Sacramento (1669-1749). Introdução, notas e sumário de Jaime Cortesão.

MANUSCRITOS DA COLEÇÃO DE ANGELIS. Cartas ânuas de la provincia Jesuítica del $\mathrm{Pa}$ raguay (1532 - 1634). Introdução de Ernesto J. A. Maeder. Buenos Aires: Academia Nacional de Historia, 1990.

MANUSCRITOS DA COLEÇÃO DE ANGELIS. Cartas ânuas de la provincia Jesuítica del Paraguay. (1632-1634) - (1637-1639). Introdução, notas e sumário de Ernesto J. A. Maeder. Buenos Aires: Academia Nacional de Historia, 1990.

MANUSCRITOS DA COLEÇÃO DE ANGELIS. Jesuitas e bandeirantes no Tape (1615-1641). Introdução, notas e sumário de Jaime Cortesão. Rio de Janeiro: Biblioteca Nacional, 1970.

MELIÁ, Bartolomeu. El guaraní: experiencia religiosa. Asunción: CEDUC-CEPAG, 1991.

MENESES, Ulpiano. A cultura material no estudo das sociedades antigas. Revista de História. USP, n. 115, p. 106-117, 1983.

MURIEL, Domingo. Historia del Paraguay desde 1747 hasta 1767. Tradução de Pablo Hernández. Madri: Libreria General de Victoriano Suárez, 1919.

PEYRET, Alejo. Cartas sobre Misiones. Buenos Aires: Imprensa de la Tribuna Nacional, 1881.

RELATÓRIO do presidente da Província de S. Pedro do Rio Grande do Sul, o senador conselheiro Manoel Antonio Galvão, na abertura da Assembléa Legislativa Provincial em 5 de outubro de 1847, acompanhado do orçamen- 
to da receita e despesa para o anno de 1847 a 1848. Porto Alegre, Typ. de Argos, 1847, p. 14. Disponível em: <http://www-apps.crl.edu/ brazil/provincial/rio_grande_do_sul>. Acesso em: 12 jan. 2017.

RELPH, Edward. Place and placelessness. London: Pilon, 1976.

SANTOS, Júlio R. Quevedo. A regulamentação do trabalho indígena nas Missões Jesuíticas. Revista Latino-Americana de História. Vol. 1, nº. 3, Março de 2012. Disponível em: <http:/ / projeto.unisinos.br/rla/index.php/rla/article/ viewFile/66/44>. Acesso em 20 jan. 2017.

SANTOS, Milton. A natureza do espaço. São Paulo: Edusp, 2014.

SIMMEL, Georg. Sociologia do espaço. Estudos Avançados. São Paulo, v. 27, 79, p. 75-112, 2013.

TYLLEY, Christopher. A Phenomenology of Landscape: places, paths and monuments. Oxford: Berg Burg Pub Ltda, 1994.

WILDE, Guillermo. Religión y poder en las misiones de guaranies. Buenos Aires: SB, 2009. 